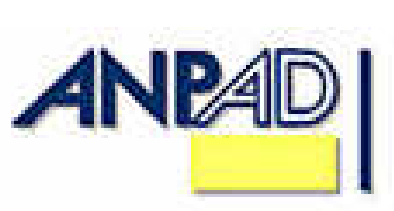

Disponível em

http://www.anpad.org.br/rac

RAC, Curitiba, v. 13, n. 1, art. 3,

p. 36-56, Jan./Mar. 2009

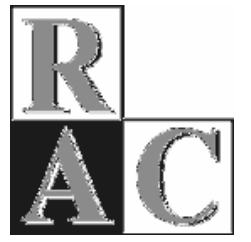

\title{
Valores Organizacionais e Criação do Conhecimento Organizacional Inovador
}

\section{Organizational Values and Innovative Organizational Knowledge Creation}

Lilian Aparecida Pasquini Miguel * Mestre em Administração de Empresas pela Universidade Presbiteriana Mackenzie.

Professora da Universidade Presbiteriana Mackenzie, São Paulo/SP, Brasil.

Maria Luisa Mendes Teixeira Doutora em Administração pela FEA/USP.

Professora da Universidade Presbiteriana Mackenzie, São Paulo/SP, Brasil.

*Endereço: Lilian Aparecida Pasquini Miguel

Rua Voltolinos, 94, apto. 83, Água Rasa, São Paulo/SP, 03179-150. E-mail: li-miguel@uol.com.br

Copyright (C 2009 RAC. Todos os direitos, inclusive de tradução, são reservados. É permitido citar parte de artigos sem autorização prévia desde que seja identificada a fonte. 


\title{
RESUMO
}

A inovação, fonte de vantagem competitiva, baseia-se na criação de conhecimento organizacional, para a qual contribui o aprendizado individual. A aprendizagem individual tradicional/comportamentalista e construtivista pode ser entendida, por extensão, como aprendizagem organizacional. O conhecimento inovador necessita que, em conjunto com as condições capacitadoras - intenção, flutuação ou caos, autonomia, redundância e variedade de requisitos - o processo de aprendizagem seja de natureza construtivista, por ser este o único capaz de gerar aprendizado de soluções novas. Os valores organizacionais são crenças que orientam o comportamento organizacional e constituem metas motivacionais. Este trabalho teve como objetivo identificar a relação entre valores organizacionais e a criação do conhecimento. A pesquisa exploratória descritiva empregou o método quantitativo. Os valores organizacionais apresentaram-se associados principalmente a aspectos de criação do conhecimento no âmbito interno das organizações. A orientação para o ambiente externo surgiu como menos relacionada aos valores organizacionais.

Palavras-chave: valores organizacionais; criação de conhecimento; aprendizagem organizacional.

\begin{abstract}
Innovation is a source of competitive advantage and is based on the continuous creation of organizational knowledge, which is supported by the individual learning. The individual learning of traditional / comportamentalist and constructivist nature can be understood, by extension, as organizational learning. The knowledge can be innovative if, along with the enabling conditions that characterize it - intention, fluctuation or chaos, autonomy, redundancy and variety of requirements - the process of learning is based on a constructivist nature, the only one capable to generate new learning solutions. The organizational values are beliefs that guide the organizations behavior and constitute motivational goals. This work had as aim to identify the relationship between organizational values and the creation of knowledge. The descriptive exploratory research used the quantitative method. The organizational values appeared in this study mainly associated to the knowledge creation aspects in the internal sphere of the organizations. The orientation towards the external environment appeared less related to the organizational values.
\end{abstract}

Key words: organizational values; knowledge creation; organizational learning. 


\section{INTRODUÇÃO}

A competitividade, encarada como a forma de as organizações sustentarem suas posições mercadológicas (Coutinho, 1994; Coutinho \& Ferraz, 1995; Ferraz, Kupfer, \& Haguenauer, 1996), traz em seu bojo a necessidade de criação e renovação de vantagens competitivas.

A inovação é considerada uma fonte de vantagem competitiva (Coutinho \& Ferraz, 1995; Porter, 1992). Consiste em uma melhoria incremental ou radical feita pelas organizações em seus produtos, tecnologias ou processos, e é produto da interação dos conhecimentos de vários agentes internos e externos à organização (Freeman, 1988; Ludvall, 1992).

Inovação e competitividade são conceitos interligados e atrelados ao desempenho das empresas. A inovação tem sua base no conhecimento e no aprendizado organizacional contínuo para garantir a longevidade empresarial e exige que as empresas desenvolvam capacidades direcionadas à criação de conhecimento - envolvendo a criação, a difusão e sua incorporação a produtos, serviços e sistemas (Nonaka \& Takeuchi, 1997).

Nonaka e Takeuchi (1997) afirmaram que para a criação do conhecimento organizacional ocorra são necessárias condições que capacitem a empresa e conversões entre conhecimento tácito e explícito. $\mathrm{O}$ processo de aprendizagem pode ser visto como parte das condições que favorecem a criação do conhecimento, desde que resulte continuamente em aprendizado inovador. Uma organização que é capaz de aprender é habilitada a criar, adquirir, transferir conhecimento e modificar seu comportamento para refletir novo conhecimento e insights (Garvin, 1993).

A criação de conhecimento se dá por meio de processos de aprendizagem, a qual é crítica para que a inovação ocorra (Saban, Lanasa, Lackman, \& Pease, 2000). As organizações aprendem a partir de seus indivíduos, o que faz com que o aprendizado individual seja imprescindível ao aprendizado organizacional (Kim, 1993).

Seguindo este raciocínio, é possível dizer que o aprendizado individual pode contribuir para o organizacional, este para a criação do conhecimento, e este, por sua vez, contribui para a inovação. Portanto, a aprendizagem individual contribui para a aprendizagem organizacional, que antecede a criação do conhecimento organizacional, fator gerador de inovação, em um processo contínuo.

Mas qual aprendizado contribuirá para o aprendizado organizacional inovador? Poderá levar à inovação um aprendizado em que o conhecimento é transmitido de forma a fazer com que o aprendiz reproduza meros padrões de comportamento?

Drucker (1991) definiu conhecimento como sendo "informação que modifica algo ou alguém - seja inspirando ação, seja tornando uma pessoa (ou uma instituição) capaz de agir de maneira diferente e mais eficaz" (p. 214). À luz desse autor não é o conhecimento repetitivo, adquirido em processos de aprendizagem que conduzem à repetição, que tem potencial para levar uma empresa a inovar.

A aprendizagem organizacional ocorre em três níveis: do indivíduo, do grupo, e da organização (Crossan, Lane, \& White, 1999; Fleury \& Oliveira, 2002; Walch \& Rivera, 1991), o que faz com que o conhecimento flua do indivíduo para o grupo, e então para a organização. A aprendizagem individual pode ser considerada, portanto, no âmbito das organizações, o nível individual da aprendizagem organizacional.

A aprendizagem individual pode ser analisada à luz de várias abordagens, que, porém, podem ser classificadas em dois grandes conjuntos: tradicional-comportamental e construtivista. $\mathrm{O}$ primeiro contempla a reprodução de aprendizado e, portanto, de conhecimento já existente; o segundo, um processo ativo, em que o sujeito, em interação com outros, gera conhecimento novo (Mizukami, 1986). Da mesma forma, a aprendizagem organizacional pode ser considerada sob essas duas 
perspectivas. Fleury e Oliveira (2002) consideram que as discussões sobre aprendizagem organizacional se têm pautado principalmente pela abordagem cognitivista, de natureza construtivista.

O conhecimento diz respeito a crenças e compromissos, ou intenção específica, e está essencialmente relacionado à ação humana (Nonaka \& Takeuchi, 1997). Tamayo e Borges (2001) propuseram que os valores organizacionais são crenças relativas a "condutas e metas organizacionais desejáveis que orientam a vida da organização" (p. 343) e que, como entenderam Meglino e Ravlin (1998), têm a função de integrar a organização internamente e adaptá-la ao ambiente externo. Portanto, é possível pensar que a criação do conhecimento organizacional e, em última instância, a inovação, sofre a influência dos valores organizacionais.

Para este trabalho, propôs-se o seguinte problema de pesquisa: existe relação entre os valores organizacionais e a criação do conhecimento organizacional? E como hipótese: os valores organizacionais correlacionam-se positivamente com a criação do conhecimento organizacional. A criação do conhecimento está aqui entendida como compreendendo as condições que a favorecem, incluindo processo de aprendizagem gerador de conhecimento inovador e processos de conversão do conhecimento.

Assumiu-se para esta pesquisa o objetivo de analisar as relações entre os valores organizacionais e a criação do conhecimento, mediante o alcance de dois objetivos específicos: verificar a existência de associações (a) entre os valores organizacionais e o processo de conversão do conhecimento e (b) entre os valores organizacionais e as condições capacitadoras para a criação do conhecimento, incluindo o processo de aprendizagem.

Espera-se com este estudo contribuir para a compreensão do papel desempenhado pelos valores organizacionais na criação do conhecimento, inovação e competitividade empresarial.

\section{DA APRENDIZAGEM INDIVIDUAL À CRIAÇÃO DO CONHECIMENTO}

Campos (2001) destacou que o aprendizado considerado revolucionário ocorre no âmbito individual e organizacional, demandando competências de criatividade, aprendizagem e inovação, no processo de busca pelo equilíbrio entre a ordem e o caos.

Saban et al. (2000) enfatizaram que, devido à aprendizagem organizacional ser crítica para que a inovação ocorra, antes de tentarem melhorar seu processo de inovação, as empresas deveriam rever seu processo de aprendizagem.

A aprendizagem organizacional ocorre nos níveis individual, grupal e organizacional; este último ocorre quando o processo de aprendizagem individual, compartilhado com o grupo, se torna institucionalizado (Fleury \& Oliveira, 2002). A influência do nível individual da aprendizagem sobre o nível organizacional acontece diante da impossibilidade de as organizações criarem conhecimento sem os indivíduos e a interação entre eles (Kolb, 1997).

As abordagens de aprendizagem individual podem ser classificadas em dois conjuntos: tradicionalcomportamentalista e construtivista. O primeiro, tradicional-comportamentalista, considera o processo ensino-aprendizagem uma prática de transmissão de conhecimento existente com ênfase no passado e em modelos a serem imitados, como respostas para o futuro. O indivíduo é um receptor passivo capaz de armazenar informações. A abordagem comportamental caracteriza-se pela ênfase em padrões esperados de comportamento, modelados pelo treinamento e controle, por punição e recompensa (Mizukami, 1986). Nestes processos não há criação de conhecimento, propriamente dita, mas apenas reaplicação do conhecimento existente (Tabela 1). 


\section{Tabela 1: As Abordagens Tradicional-comportamental e Construtivista para a Geração do Conhecimento}

\begin{tabular}{|c|c|}
\hline Tradicional & $\begin{array}{l}\text { - inteligência para acumular, armazenar informação e incorporá-la; } \\
\text { - decomposição da realidade para simplificá-la; ensino dedutivo; } \\
\text { - preocupação com o passado, modelo a ser imitado no futuro. }\end{array}$ \\
\hline Comportamentalista & $\begin{array}{l}\text { - baseado na experiência planejada; } \\
\text { - resultado direto dela; não preocupação com o processo de } \\
\text { aprendizagem; } \\
\text { - ênfase no comportamento observável; } \\
\text { - estímulos e respostas; estados internos não relevantes para a análise } \\
\text { funcional; } \\
\text { - estruturado, indutivamente, via experiência. }\end{array}$ \\
\hline Humanista & $\begin{array}{l}\text { - experiência pessoal e subjetiva é a base para o conhecimento abstrato, } \\
\text { sem modelos ou regras; } \\
\text { - a percepção é a realidade; o homem tem papel central e primordial na } \\
\text { elaboração e na CRIAÇÃO DO CONHECIMENTO; } \\
\text { - ao experimentar, o homem conhece; experiência = conjunto de } \\
\text { realidades vividas, com significados reais e concretos, ponto de partida } \\
\text { para a mudança e crescimento - nada é acabado e o conhecimento é } \\
\text { dinâmico; } \\
\text { - o conhecimento é inerente à atividade humana; } \\
\text { - o único ser que educa é o que aprendeu a aprender; } \\
\text { - a motivação é inerente e intrínseca ao ser. }\end{array}$ \\
\hline Cognitiva & $\begin{array}{l}\text { - construção continua (desenvolvimento de novas estruturas no ser); } \\
\text { - resultado da interação sujeito-objeto; } \\
\text { - conhecer algo é agir sobre ele e transformá-lo; } \\
\text { - conhecer é assimilar o real às estruturas da transformação, as quais } \\
\text { são elaboradas pela inteligência enquanto prolongamento direto da } \\
\text { ação (Piaget); } \\
\text { - aquisição: exógena (constatação, cópia, repetição) e endógena } \\
\text { (compreensão das relações e combinações); } \\
\text { - o verdadeiro conhecimento reside na Segunda fase (abstração } \\
\text { empírica ou reflexiva) - busca de estado final de equilíbrio nunca } \\
\text { alcançado; } \\
\text { - a busca cria novas estruturas mentais (construtivismo interacionista, } \\
\text { que sempre cria algo novo no processo para continuar existindo). }\end{array}$ \\
\hline
\end{tabular}

Fonte: elaborado pela autora, com base em Mizukami (1986, pp. 7-83).

Considerando o ambiente organizacional, das abordagens construtivistas existentes, destacam-se neste trabalho duas: a humanista e a cognitivista, que consideram o individuo como ativo no processo de aprendizagem: a) humanista, onde o indivíduo reconstrói em si o mundo exterior, partindo de sua percepção; b) a cognitivista, o aprendizado é fruto da interação... O construtivismo sugere que o ser humano reconstrói em si o mundo exterior, partindo de sua percepção e o conhecimento é adquirido num processo contínuo e interativo (Mizukami, 1986) (Tabela 1).

Assim como a aprendizagem individual, a organizacional também pode ser analisada sob a perspectiva tradicional-comportamentalista e sob a construtivista, esta última gerando conhecimento novo e possibilitando a inovação. Essas perspectivas podem ser percebidas como subjacentes às abordagens de Argyris e Schon (1978) e Kim (1993).

Argyris e Schon (1978) classificaram o processo de aprendizagem organizacional em três estágios de evolução: aprendizagem de circuito simples, focada em ações corretivas; de circuito duplo, envolvendo uma reflexão por parte do indivíduo, fazendo com que o conhecimento passe a fazer parte da organização; circuito triplo (deutero-aprendizagem), onde a organização aprende a aprender e a avaliar o sistema de aprendizagem em si. 
Kim (1993) vê a aprendizagem organizacional em dois passos simultâneos: a operacionalização efetiva da ação permite que se aprenda o como, enquanto a reflexão sobre isso possibilite o porquê, pela observação e formação dos conceitos.

A inovação como estratégia de competitividade empresarial exige a criação de conhecimento novo, portanto criado a partir de processos de aprendizagem individual e organizacional que contemplem a reflexão e o questionamento.

Embora diversos autores abordem a questão do conhecimento, sua geração, gestão, estratégias, tais como Kogut e Zander (1992), Bierly e Chakrabarti (1996), Spender e Grant (1996), Leonard e Sensiper (1998), Bontis (1999), Zack (1999), Nonaka, Toyama e Konno (2000), Krogh, Ichijo e Nonaka (2001) entre outros, o processo de criação do conhecimento tem em Nonaka (1997) não somente seu autor seminal, mas também o autor de maior expressão em relação ao tema, razão pela qual foi adotado como o direcionador deste estudo.

Nonaka e Takeuchi (1997) fundamentaram o processo de criação do conhecimento organizacional em duas dimensões - epistemológica e ontológica - refletidas pelo processo de conversão do conhecimento e pelas condições capacitadoras. Essas dimensões incorporam o conhecimento tácito, calcado na estrutura cognitiva do indivíduo e expandido por meio da interação social, fazendo com que aprender seja uma experiência única e individual, em que a inovação ocorre na recriação do ser e do mundo que o cerca, por meio do processo de conversão do conhecimento.

A conversão do conhecimento envolve a interação do conhecimento tácito e do conhecimento explícito, gerando quatro diferentes processos: socialização (tácito em tácito), externalização (tácito em explícito), combinação (explicito em explícito), e internalização (explícito em tácito). As condições organizacionais capacitadoras - intenção, flutuação ou caos, autonomia, redundância e variedade requisitos - permitem que os quatro modos de conversão sejam transformados em uma espiral do conhecimento. Este processo ocorre em cinco fases - compartilhamento do conhecimento tácito, criação de conceitos, justificação de conceitos, construção de um arquétipo e difusão interativa do conhecimento, gerando uma segunda espiral, que, combinada à primeira, gera a inovação (Nonaka \& Takeuchi, 1997).

A criação do conhecimento implica a existência de pré-requisitos organizacionais, como a exigência de que a empresa tenha uma visão e metas que dêem origem às suas diretrizes (intenção), em um ambiente que contemple a liberdade de criação (autonomia); possua interação com o ambiente externo (flutuação e caos criativo); disponibilidade plena de informação além da necessidade imediata (redundância); e diversidade interna, refletindo no ambiente interno a variedade encontrada no ambiente externo - variedade de requisitos (Nonaka \& Takeuchi, 1997).

A criação do conhecimento, conforme entendida por Nonaka e Takeuchi (1997), supõe um processo de aprendizagem individual em que o aprendizado seja resultado de reflexão, de criatividade, de questionamento, logo de natureza construtivista. No entanto, se a aprendizagem trata de um processo de criação do conhecimento pela transformação da experiência do indivíduo como propõe Baker, Jensen e Kolb (2002) e se transforma em aprendizado organizacional, e se o aprendizado pode ser obtido de forma a reproduzir modelos já existentes, conforme as abordagens tradicional e comportamental, então as organizações também podem gerar conhecimento entre aspas, isto é, conhecimento que não é efetivamente novo, pouco ou nada contribuindo para um processo de inovação. Assim, é possível pensar nas características da criação do conhecimento sob o ponto de vista das abordagens tradicional-comportamental, como construtivista, envolvendo tanto condições capacitadoras como o processo de conversão. Estas características estão resumidas nas Tabelas 2 e 3.

Posto isto pode-se dizer que a inovação, a criação do conhecimento e a aprendizagem organizacional sofrem influência do processo de aprendizagem individual, levado a efeito nas organizações. Em decorrência, o processo de criação do conhecimento organizacional considerado neste estudo envolve não apenas a conversão do conhecimento e condições capacitadoras propostas por Nonaka e Takeuchi (1997), mas também o processo de aprendizagem organizacional no nível individual. 
A aprendizagem organizacional no nível individual é entendida neste trabalho como a aprendizagem dos indivíduos em interação, que pode ser orientada por uma perspectiva tradicionalcomportamentalista, quanto por uma construtivista; apenas esta tem a capacidade de promover a geração de conhecimento inovador capaz de contribuir para a inovação e competitividade das organizações.

Neste trabalho, assume-se que o conhecimento gerado com vistas à inovação depende da aprendizagem organizacional a partir da individual. Logo, esse conhecimento, que depende da cognição individual, difere fundamentalmente de informação, que possui característica funcional e objetiva, servindo de base às interpretações dos indivíduos que geram o conhecimento (Daft \& Weick, 1984).

\section{VAlores Organizacionais e Metas de Conduta Organizacional}

Tamayo e Borges (2001) relatam que as organizações enfrentam três exigências fundamentais: a necessidade de compatibilizar os interesses individuais e os coletivos, uma vez que a relação entre indivíduo e grupo é inevitável; o estabelecimento de uma estrutura que garanta o alcance das metas e objetivos da organização; e o relacionamento entre a organização e o ambiente físico e social (p. 345). Os valores organizacionais, ao serem respostas a problemas concretos a partir de soluções bem sucedidas no passado (Tamayo \& Borges, 2001) orientam a satisfação dessas necessidades. 


\section{Tabela 2: As Características das Condições Capacitadoras nas Abordagens Construtivista e Tradicional/Comportamentalista}

\begin{tabular}{|c|c|c|}
\hline $\begin{array}{c}\text { Condição } \\
\text { Capacitadora }\end{array}$ & $\begin{array}{c}\text { Abordagem } \\
\text { Construtivista }\end{array}$ & $\begin{array}{l}\text { Abordagem Tradicional/ } \\
\text { Comportamentalista }\end{array}$ \\
\hline Intenção & $\begin{array}{l}\text { - Aspiração de uma empresa e dos indivíduos às suas metas. } \\
\text { - É o critério mais importante para julgar a veracidade de um } \\
\text { determinado conhecimento. } \\
\text { - Expressa diretrizes organizacionais ou visões que podem servir para } \\
\text { avaliar e justificar o conhecimento criado. } \\
\text { - Subjaz à criação do conhecimento (Polanyi, 1958). }\end{array}$ & $\begin{array}{l}\text { - Reflete a demanda de compromisso formal entre os indivíduos e os } \\
\text { valores da organização. } \\
\text { - Os resultados esperados e não as diretrizes da organização são } \\
\text { comunicadas aos funcionários. } \\
\text { - O conhecimento a ser criado é comunicado aos indivíduos } \\
\text { conforme os objetivos organizacionais. }\end{array}$ \\
\hline Autonomia & $\begin{array}{l}\text { - Aumenta a possibilidade de as pessoas se motivarem para criar novo } \\
\text { conhecimento. } \\
\text { - Não há dominação-subordinação e papéis sobrepostos. } \\
\text { - As decisões são discutidas e compartilhadas. }\end{array}$ & $\begin{array}{l}\text { - É vista como um elo frágil que gera baixa integração e } \\
\text { comprometimento. } \\
\text { - As estruturas hierárquicas formais devem ser reconhecidas e } \\
\text { respeitadas, assim como o limite do papel de cada um. }\end{array}$ \\
\hline $\begin{array}{l}\text { Flutuação e } \\
\text { Caos Criativo }\end{array}$ & $\begin{array}{l}\text { - Interação da organização com o ambiente externo. } \\
\text { - Flutuação }=\text { ordem sem recursividade, padrão difícil de prever } \\
\text { inicialmente (Gleick, 1987). } \\
\text { - Induz e fortalece o compromisso subjetivo dos indivíduos, através do } \\
\text { erro de interpretação, fazendo-os mudar seu modo de pensar, e } \\
\text { contribuindo para a externalização do conhecimento tácito. }\end{array}$ & $\begin{array}{l}\text { - É visto como sinal de baixo controle da organização sobre o } \\
\text { mercado. } \\
\text { - O ambiente externo deve ser dominado pelo poder. } \\
\text { - O erro não é bem visto como forma de experiência criadora. }\end{array}$ \\
\hline Redundância & $\begin{array}{l}\text { - Existência de mais informações que a demanda operacional imediata. } \\
\text { - superposição intencional de informação sobre atividades da empresa, } \\
\text { responsabilidades da gerência e sobre a empresa como um todo. } \\
\text { - O compartilhamento implica a possibilidade de que alguém sinta o que } \\
\text { outros estão tentando expressar e é pré-requisito para que todos sintam } \\
\text { ter a mesma importância e se podem tornar líderes do sistema. }\end{array}$ & $\begin{array}{l}\text { - Confunde o entendimento do papel de cada um, o controle e a } \\
\text { direção do pensamento e ação individuais. } \\
\text { - Nas organizações altamente hierárquicas, pode criar conflitos } \\
\text { internos. }\end{array}$ \\
\hline $\begin{array}{l}\text { Variedade de } \\
\text { requisitos }\end{array}$ & $\begin{array}{l}\text { - A diversidade interna de uma organização deve refletir a variedade e a } \\
\text { complexidade do ambiente e seus desafios (Ashby, 1956). } \\
\text { - Não deve haver diferenciais entre os níveis de informação dentro da } \\
\text { organização, com prejuízo da interação. } \\
\text {-Permite à organização reagir rapidamente a flutuações (exemplo: } \\
\text { estrutura organizacional do tipo bio funcional da Kao). }\end{array}$ & $\begin{array}{l}\text { - A organização não absorve dentro de seu ambiente interno a } \\
\text { dinamicidade do ambiente externo. } \\
\text { - Diferentes profissionais, em diferentes funções, recebem apenas a } \\
\text { informação de que necessitam para seu trabalho. } \\
\text { - A estrutura organizacional não reflete o ambiente externo em sua } \\
\text { alocação de recursos, tornando-a pouco ágil. }\end{array}$ \\
\hline
\end{tabular}

Fonte: elaborado pelas autoras, com base em Mizukami (1986, pp. 7-83) e Nonaka e Takeuchi (1997, pp. 1-102). 
Tabela 3: As Características Construtivista e Tradicional/Comportamentalista de Aprendizagem e os Modos e Fases de Conversão do Conhecimento

\begin{tabular}{|c|c|c|}
\hline Processo & $\begin{array}{l}\text { Abordagem } \\
\text { Construtivista }\end{array}$ & $\begin{array}{l}\text { Abordagem Tradicional/ } \\
\text { Comportamentalista }\end{array}$ \\
\hline $\begin{array}{l}\text { Socialização: de } \\
\text { Tácito para Tácito } \\
\text { (Compartilhamento) }\end{array}$ & - Compartilhamento de experiências. & $\begin{array}{l}\text { - não é preciso usar a linguagem - ex. Aprendizes e seus mestres; } \\
\text { - observação, imitação prática. }\end{array}$ \\
\hline $\begin{array}{l}\text { Externalização: de } \\
\text { Tácito para Explícito } \\
\text { (Criação Conceitos) }\end{array}$ & $\begin{array}{l}\text { - Articulação do conhecimento tácito. } \\
\text { - processo de criação de conhecimento, expresso em metáforas, } \\
\text { analogias, conceitos, hipóteses ou modelos. } \\
\text { - a discrepância entre a linguagem e imagem gera reflexões e interações } \\
\text { das pessoas. } \\
\text { - o homem está envolto no processo de criação de conceitos. } \\
\text { - diálogo ou reflexões coletivas; envolve indução e dedução. } \\
\text { - a externalização é a chave para a criação do conhecimento, pois cria } \\
\text { conceitos novos e explícitos a partir do conhecimento tácito. } \\
\text { - metáfora - não existindo nada a priori; já a analogia liga a algo similar: } \\
\text { algo a priori; símbolos que criam novas interpretações da experiência } \\
\text { pedindo ao ouvinte que veja uma nova relação entre as coisas. } \\
\text { - criam novas formas de experimentar a realidade. }\end{array}$ & \\
\hline $\begin{array}{l}\text { Combinação: de } \\
\text { Explícito para } \\
\text { Explícito (Construção } \\
\text { de Arquétipo) }\end{array}$ & $\begin{array}{l}\text { - Novo conhecimento através da combinação e interação de conceitos } \\
\text { intermediários (conceito de produto, por exemplo) a conceitos principais } \\
\text { (visão da empresa, por exemplo). }\end{array}$ & $\begin{array}{l}\text { - Sistematização de conceitos em um sistema de conhecimento; } \\
\text { - combina conjuntos diferentes de conhecimento explícito; } \\
\text { - encontrada na educação e no treinamento formais. }\end{array}$ \\
\hline $\begin{array}{l}\text { Internalização: de } \\
\text { Explícito para Tácito } \\
\text { (Justificação de } \\
\text { Conceitos) }\end{array}$ & $\begin{array}{l}\text { - Expansão do escopo da experiência prática é essencial para a } \\
\text { internalização. }\end{array}$ & $\begin{array}{l}\text { - Incorporação do conhecimento explícito no tácito - intimamente } \\
\text { relacionada ao aprender fazendo, sob a forma de modelos mentais } \\
\text { ou know-how técnico compartilhado, e é preciso que o conhecimento } \\
\text { seja verbalizado, diagramado e documentado (manuais, documentos, } \\
\text { histórias orais). } \\
\text { - a internalização também pode ocorrer sem a "re-experimentação" } \\
\text { das experiências de outrem, através da leitura ou conhecimento de } \\
\text { uma história de sucesso. }\end{array}$ \\
\hline
\end{tabular}

Fonte: elaborado pelas autoras, com base em Mizukami (1986, pp. 7-83) e Nonaka e Takeuchi (1997, pp. 1-102). 
Valores organizacionais são "princípios ou crenças, organizados hierarquicamente, relativos a condutas ou metas organizacionais desejáveis, que orientam a vida da organização e estão a serviço de interesses individuais, coletivos ou ambos" (Tamayo \& Borges, 2001, p. 343) e podem explicar os fenômenos organizacionais (Connor \& Becker, 1975).

De acordo com Mendes e Tamayo (1999), os valores "fazem parte de uma dialética de manutenção e de transformação dos comportamentos humanos pela socialização e aprendizagem permanentes, sendo, por isso, valiosos para as instituições que desejam modelar comportamentos em função de seus interesses" (p. 3).

Tamayo e Gondim (1996) argumentaram que os valores organizacionais possuem três aspectos básicos: (a) cognitivo - "representam respostas cognitivas prontas e privilegiadas a problemas organizacionais"; (b) motivacional - expressam interesses e metas fundamentais; e (c) organização hierárquica - expressam preferências por determinadas condutas, metas ou estratégias em detrimento de outras.

Oliveira e Tamayo (2004), ao estudarem valores organizacionais, tendo como base a relação destes com valores pessoais básicos do indivíduo segundo Schwartz (1992), propuseram a seguinte estrutura para os valores organizacionais, composta por oito tipos motivacionais.

Fator 1 - Realização: a valorização da competência para o alcance do sucesso da organização e dos empregados.

Fator 2 - Conformidade: valorização do respeito às regras e modelos de comportamento no ambiente de trabalho e no relacionamento com outras organizações.

Fator 3 - Domínio: valorização do poder, tendo como meta a obtenção de status, controle sobre pessoas, recursos e mercado.

Fator 4 - Bem-estar: valorização da satisfação dos empregados mediante a qualidade de vida no trabalho.

Fator 5 - Tradição: valorização dos costumes e práticas consagradas.

Fator 6 - Prestígio: valorização do prestígio organizacional na sociedade, mediante a qualidade de produtos.

Fator 7 - Autonomia: valorização de desafios, a busca de aperfeiçoamento constante, a curiosidade, a variedade de experiências e a definição de objetivos profissionais dos empregados.

Fator 8 - Preocupação com a coletividade: valorização do relacionamento com pessoas que estão próximas da comunidade.

Esses fatores de valores organizacionais têm sua origem nos valores pessoais e ambos possuem características comuns, uma vez que ambos possuem, entre outros, componentes motivacionais e a função de orientar comportamentos: os valores pessoais orientam a vida das pessoas e os organizacionais a vida das organizações (Oliveira \& Tamayo, 2004).

Com base nessas premissas, Oliveira e Tamayo (2004) associaram os fatores de valores organizacionais à estrutura básica de valores pessoais de Schwartz (1992), alinhando-as às dimensões básicas bipolares: Conservação versus Abertura à Mudança e Autopromoção versus Autotranscendência.

A dimensão Conservação versus Abertura à Mudança opõe valores que enfatizam a independência de ação a valores que se referem à preservação de práticas tradicionais e proteção da estabilidade. Os 
valores organizacionais Tradição e Conformidade encontram-se, neste caso, opostos à Autonomia, respectivamente pertencentes às dimensões Conservação versus Abertura à Mudança (Oliveira \& Tamayo, 2004).

A dimensão Autopromoção versus Autotranscendência opõe valores que privilegiam interesses individuais, mesmo que à custa de valores de outras pessoas e valores que enfatizam a preocupação com o bem-estar dos outros e da natureza. Prestígio, Domínio, Realização e Bem-Estar são valores organizacionais que correspondem à dimensão autopromoção, opondo-se à Preocupação com a Coletividade, pertinentes à dimensão Autotranscendência.

Tendo em vista que as condições que contemplam a criação do conhecimento devem privilegiar a interação social, tanto a criatividade, quanto a integração entre as aspirações pessoais e as metas organizacionais (Nonaka \& Takeuchi, 1997), seriam, em princípio, os valores relativos à abertura, à mudança, autopromoção e preocupação com a coletividade que estariam associados a fatores de criação do conhecimento, como as condições capacitadoras e processos de conversão.

\section{Procedimentos Metodológicos}

A pesquisa caracterizou-se como exploratório-descritiva e empregou o método quantitativo, coletando dados mediante questionário fechado, do qual fez parte um bloco formado por valores organizacionais e outro composto por assertivas relativas à criação do conhecimento, além de um terceiro destinado a variáveis demográficas.

Para a coleta dos valores organizacionais, utilizou-se o Inventário de Perfis de Valores Organizacionais [IPVO] desenvolvido por Oliveira e Tamayo (2004). Para coletar dados referentes à criação do conhecimento, foi necessário construir uma escala, o que envolveu os seguintes procedimentos: a) construção de assertivas a partir do referencial teórico relativo à criação do conhecimento organizacional e às abordagens de aprendizagem individual, com base, respectivamente, em Nonaka e Takeuchi (1997) e Mizukami, (1986); b) comunização, evitando-se a repetição de idéias; c) revisões da redação das assertivas e comunização, num total de sete, visando atender às exigências técnicas.

Às assertivas relativas à criação do conhecimento acoplou-se uma escala do tipo Likert de sete pontos, seguindo a mesma estrutura do IPVO, procurando evitar dificuldades de entendimento. Assim como o IPVO, a escala para mensurar a criação do conhecimento foi assumida como intervalar, uma vez que isto não causa diferenças importantes, como afirmou Selltiz (1967).

O processo de validação do conteúdo ocorreu em duas etapas. A primeira consistiu na validação do conteúdo das assertivas relativas às abordagens de aprendizagem organizacional, submetendo-as à análise de um especialista na área de Educação. A segunda, do questionário como um todo. Nesta etapa foram enviados 21 questionários para profissionais, cujos níveis variaram de estagiários a diretores, na faixa de 24 a 58 anos, de empresas de atividades diferentes entre si, todos eles com pelo menos o terceiro grau completo ou em finalização, e nenhum deles cursando ou tendo cursado qualquer mestrado acadêmico, para minimizar qualquer interferência ou viés na análise das assertivas. Houve o retorno de 17 respostas, sendo quatro sem nenhuma dúvida ou comentário, e 13 com observações e questionamentos, que foram discutidos e aclarados posteriormente com os respondentes, tendo sido as sugestões acatadas.

Os questionários, autopreenchíveis, foram entregues pessoalmente, num total de 410, ao responsável da área de Desenvolvimento de Produto de cada uma das oito empresas pesquisadas, e retirados, também pessoalmente, junto a esses mesmos responsáveis, 106 de 410, tendo-se obtido uma taxa de retorno de $25 \%$. 
A amostra não-probabilística tinha como público-alvo funcionários efetivos, o que excluiu os terceirizados ou temporários, pertencentes a todo e qualquer nível hierárquico de setores funcionais da organização diretamente relacionados ao desenvolvimento de novos produtos, mesmo que em atividades de suporte.

A escolha da área de desenvolvimento de produtos teve como justificativa o fato de ser uma área onde a inovação ocorre e, portanto, a criação do conhecimento.

A análise das respostas relativas ao perfil dos respondentes, nos 106 questionários recebidos, permitiu identificar que 61,9\% dos respondentes trabalhavam em funções técnicas, enquanto 30,5\% em função gerencial, e os restantes 7,6\%, em funções administrativas; $65,7 \%$ pertenciam à área de desenvolvimento de novos produtos, propriamente dita; $28,6 \%$ atuavam em áreas ligadas ao desenvolvimento de produto (Vendas, Marketing e Serviços); e os restantes 5,7\% em áreas administrativas relacionadas ao desenvolvimento de produto. No tocante à idade, $39 \%$ dos respondentes tinham entre 36 e 45 anos; $27,6 \%$ entre 26 e 35 anos; $19 \%$ entre 46 e 60 anos; 13,3\% entre 18 e 25 anos; e o $1 \%$ restante mais de 60 anos; $65,7 \%$ pertenciam ao sexo masculino e $34,3 \%$ ao sexo feminino; e 54,3\% trabalhavam de 1 a 10 anos na organização; $21,9 \%$ de 11 a 20 anos; $16,2 \%$ há mais de 21 anos; e apenas 7,6\% trabalham há menos de 1 ano.

A amostra foi considerada adequada à análise a que se propôs este estudo, enquadrando-se no público-alvo previsto.

O tratamento de dados ocorreu em várias etapas. A primeira correspondeu à verificação de que os respondentes se enquadravam nos critérios estabelecidos previamente no plano amostral; a segunda, à verificação da existência de valores faltantes na amostra, bem como à existência de casos e variáveis outliers; na terceira procedeu-se à análise fatorial da escala de Criação do Conhecimento Organizacional, visando à redução do número de assertivas a serem utilizadas nas demais análises estatísticas; e na última foi feita uma análise de correlação bivariada entre as assertivas relativas à criação do conhecimento e os valores organizacionais, utilizando-se o coeficiente de Pearson, visando à investigação do problema de pesquisa e da hipótese propostos para o estudo.

\section{APRESENTAÇÃO, ANÁLISE E INTERPRETAÇÃO DOS DADOS}

Antes do tratamento e análise dos dados propriamente ditos, procedeu-se à preparação deles quanto a valores faltantes, que causou a exclusão de um questionário, e análise de variáveis e casos outliers.

Foram analisadas as variáveis outliers apenas para a escala de Criação do Conhecimento Organizacional, uma vez que a de Valores Organizacionais (Oliveira \& Tamayo, 2004) é uma escala validada, tendo-se verificado que nenhuma variável apresentou uma quantidade de outliers superior a $2 \%$.

A análise dos casos outliers não revelou nenhum nessas condições, uma vez que aqueles que apresentaram variáveis com valores outlier - sete casos - o fato ocorreu em uma variável, não devendo ser descartados, portanto, conforme sugere Hair, Anderson, Taham e Black (2005).

A amostra composta por 105 casos apresentou um índice de poder $=0.88$, posicionando-se acima de 0.8 , limite sugerido por Hair et al (2005), com alfa de 0.05 , e tamanho do efeito com $\mathrm{r}=0.03$, tornando a amostra em questão sensível a diferenças pequenas. 


\section{Escala de CriaçÃo do ConheCimento Organizacional InOvador: ANálise FATORIAL}

A análise dos fatores foi realizada com base nas características das abordagens tradicional/comportamentalista e construtivista, e os modos e fases que compõem o processo de criação do conhecimento. As Tabelas 2 e 3 mostram as características dessas abordagens dentro de cada uma das fases do processo de conversão, à luz das abordagens Tradicional/Comportamentalista e Construtivista, respectivamente.

Visando à redução do número de variáveis da escala de Criação do Conhecimento Organizacional, utilizou-se a rotação VARIMAX com extração de componentes principais.

Para o desenvolvimento da análise fatorial, seguiram-se os passos indicados por Hair, Anderson, Tatham e Black (1998). O teste de esfericidade de Bartlet indicou serem os dados adequados para a realização da análise fatorial e foram excluídas 11 variáveis, cujos valores de MSA se apresentaram inferiores a 0,8 .

Ressalta-se que o questionário possuía 43 assertivas; 60\% correspondiam à abordagens construtivistas e, após a análise fatorial; $72 \%$ das 32 variáveis restantes situavam-se nessa perspectiva, sugerindo a possibilidade de maior tendência da amostra para um pensamento alinhado com o construtivismo. Este aspecto foi reforçado pelo fato de que a maioria das assertivas excluídas diziam respeito à abordagem tradicional/comportamentalista.

A análise fatorial com rotação ortogonal VARIMAX, seguida da rotação oblíqua PROMAX, procedimento de validação proposto por Hair et al. (1998), apontou uma solução de cinco fatores, com eingenvalue superior a 1, índices de confiabilidade Alpha de Cronbach acima de 0,7 e explicando 65,2\% da variância, tendo-se obtido um KMO de 0,917 (Tabela 4).

Tabela 4: Fatores da Escala de Criação do Conhecimento Inovador

\begin{tabular}{c|c|c|c|c}
\hline Fator & Eingenvalue & \% da variância & \% Variância acumulada & Alpha de Chronbach \\
\hline 1 & 15,085 & 47,1 & 47,1 & 0,9149 \\
2 & 1,916 & 6,0 & 53,1 & 0,9101 \\
3 & 1,495 & 4,7 & 57,8 & 0,8740 \\
4 & 1,213 & 3,8 & 61,6 & 0,8376 \\
5 & 1,145 & 3,6 & 65,2 & 0,7539 \\
\hline
\end{tabular}

Fonte: dados da pesquisa.

Fator 1 - Estímulo ao Enfrentamento de Desafios: combinou condições para a criação do conhecimento e aprendizagem individual, com destaque para a abordagem construtivista (Tabela 5); Fator 2 - Compromisso Consciente com a Empresa: refere-se ao compromisso consciente do empregado com o alcance dos objetivos da empresa. Caracteriza-se pelas condições capacitadoras para a criação do conhecimento, e pela abordagem tradicional de aprendizagem (Tabela 5); Fator 3 Processo Decisório Participativo: caracteriza-se pelas condições capacitadoras para a criação do conhecimento, e pela abordagem construtivista. Refere-se ao processo decisório caracterizado pela participação de pessoas de diversos níveis hierárquicos na busca de soluções em conjunto, num 
ambiente de mútua cooperação, em que existe abundância de informações sobre a empresa e se estimula a discussão das visões pessoais acerca do ser humano e da vida, e se consideram as aspirações pessoais na definição de metas organizacionais (Tabela 5); Fator 4 - Conversão do Conhecimento: contemplou apenas assertivas relativas ao processo de conversão do conhecimento, indicando que a forma como o conhecimento é compartilhado, ou seja, a forma como as pessoas aprendem, tem ligação direta com o processo de criação do conhecimento organizacional. Caracterizase pelo compartilhamento de idéias, criatividade, questionamento sobre o statu quo e busca de informações (Tabela 5); Fator 5 - Orientação ao Ambiente Externo: caracteriza-se pelas condições capacitadoras para a criação do conhecimento e abordagem construtivista. Sugere preocupação da empresa para com as mudanças que ocorrem no ambiente externo, às quais se antecipa mediante a aquisição do conhecimento. Encontra-se nesta dimensão uma orientação que parte da empresa para o indivíduo, exigindo flexibilidade e proatividade para lidar com a mudança (Tabela 5).

\section{Tabela 5: Fatores de Criação do Conhecimento}

\begin{tabular}{|c|c|c|c|}
\hline \multirow[t]{2}{*}{$\mathbf{C F}$} & Assertiva & \multirow[t]{2}{*}{ DC } & \multirow[t]{2}{*}{ CA. } \\
\hline & Fator 1 - Estímulo ao Enfrentamento de Desafios & & \\
\hline 0,75 & $\begin{array}{l}\text { A empresa contempla no ambiente interno a diversidade de recursos (tecnológicos, } \\
\text { físicos e humanos) encontrados no ambiente externo }\end{array}$ & $\mathrm{CC}$ & Constr. \\
\hline 0,72 & $\begin{array}{l}\text { As pessoas são incentivadas a assumir novos desafios, como fonte de experiência e } \\
\text { evolução pessoal e profissional }\end{array}$ & A & Constr. \\
\hline 0,64 & $\begin{array}{l}\text { As pessoas são incentivadas a considerar seus insights e percepções em suas } \\
\text { atividades profissionais }\end{array}$ & A & Constr. \\
\hline 0,64 & Todos os funcionários são avaliados com base nas metas que lhes foram atribuídas & A & Trad. \\
\hline 0,62 & $\begin{array}{l}\text { Cada pessoa recebe a quantidade de informação necessária para que obtenha os } \\
\text { resultados esperados no exercício de sua função }\end{array}$ & $\mathrm{CC}$ & Constr. \\
\hline 0,53 & $\begin{array}{l}\text { As pessoas buscam criar soluções que as façam sentir-se seguras quanto ao futuro da } \\
\text { empresa. }\end{array}$ & A & Constr. \\
\hline 0,47 & A disciplina e a organização são valores importantes dentro da empresa & A & Trad. \\
\hline 0,46 & $\begin{array}{l}\text { A empresa valoriza o dinamismo e a flexibilidade para absorver mudanças do } \\
\text { ambiente externo }\end{array}$ & $\mathrm{CC}$ & Constr. \\
\hline 0,45 & timuladas a criar novos conhecimentos através de discussões & $\mathrm{C}$ & Constr. \\
\hline 0,43 & $\begin{array}{l}\text { es que equilibrem o discurso e a prática } \\
\text { a Empresa }\end{array}$ & A & Constr. \\
\hline 0,98 & As $\mathrm{p}$ & $\mathrm{CC}$ & Trad. \\
\hline 0,84 & $\begin{array}{l}\text { As pessoas estão atentas ao conhecimento que precisa ser criado para atender aos } \\
\text { objetivos da empresa }\end{array}$ & $\mathrm{CC}$ & Trad. \\
\hline 0,69 & seguidas são claramente comunicadas a toda a organização & $\mathrm{CC}$ & Constr. \\
\hline 0,67 & As 1 & $\mathrm{CC}$ & Constr. \\
\hline 0,67 & O conhecimento & $\mathrm{C}$ & Trad. \\
\hline 0,45 & $\begin{array}{l}\text { As gerências enfatizam a importância de nosso compromisso com os valores } \\
\text { fundamentais da empresa } \\
\text { Fator } 3 \text { - Processo Decisório Participativo }\end{array}$ & $\mathrm{CC}$ & Trad. \\
\hline 1,00 & das decisões de diversos níveis hierárquicos & $\mathrm{CC}$ & Constr. \\
\hline 0,66 & $\begin{array}{l}\text { As gerências estimulam discussões sobre nossa visão pessoal a respeito do ser } \\
\text { humano e da vida }\end{array}$ & $\mathrm{CC}$ & Constr. \\
\hline 0,64 & $\begin{array}{l}\text { As aspirações dos funcionários são consideradas para a definição das metas } \\
\text { organizacionais }\end{array}$ & $\mathrm{CC}$ & Constr. \\
\hline 0,63 & $\begin{array}{l}\text { As pessoas têm mais informações sobre toda a empresa do que aquelas de que } \\
\text { precisam }\end{array}$ & $\mathrm{CC}$ & Constr. \\
\hline 0,44 & s, nos reunimos para encontrar soluções em conjunto & A & Constr. \\
\hline 0,42 & $\begin{array}{l}\text { As pessoas sentem-se estimuladas a colaborar mutuamente por terem o mesmo nível } \\
\text { de informação }\end{array}$ & A & Constr. \\
\hline 0,40 & $\begin{array}{l}\text { As pessoas são motivadas a interagir umas com as outras, não importando a que áreas } \\
\text { ou funções pertençam }\end{array}$ & $\mathrm{CC}$ & Constr. \\
\hline
\end{tabular}


(conclusão)

Tabela 5: Fatores de Criação do Conhecimento

\begin{tabular}{|c|c|c|c|}
\hline \multirow[t]{2}{*}{$\mathbf{C F}$} & Assertiva & \multirow[t]{2}{*}{ DC } & \multirow[t]{2}{*}{ CA. } \\
\hline & Fator 4 Conversão do Conhecimento & & \\
\hline 0,78 & $\begin{array}{l}\text { As pessoas são treinadas de forma coletiva para garantir que todos recebam o mesmo } \\
\text { tipo de informação }\end{array}$ & $\mathrm{C}$ & Trad. \\
\hline 0,76 & As pessoas compartilham as suas experiências com as outras & $\mathrm{C}$ & Constr. \\
\hline 0,63 & $\begin{array}{l}\text { As pessoas são incentivadas a adquirir as informações necessárias para o alcance dos } \\
\text { objetivos }\end{array}$ & $\mathrm{C}$ & Trad. \\
\hline 0,52 & As pessoas são estimuladas a fazer as coisa de formas diferentes & $\mathrm{C}$ & Constr. \\
\hline 0,48 & $\begin{array}{l}\text { As pessoas são incentivadas a questionar informações e conceitos preestabelecidos } \\
\text { Fator } 5 \text { - Orientação ao Ambiente Externo. }\end{array}$ & $\mathrm{C}$ & Constr. \\
\hline 0,76 & A empresa está atenta ao que se passa no ambiente externo & $\mathrm{CC}$ & Constr. \\
\hline 0,70 & A empresa faz mudanças internas conforme o que prevê no ambiente externo & $\mathrm{CC}$ & Constr. \\
\hline 0,47 & As pessoas possuem autonomia para criar novos conhecimentos & $\mathrm{CC}$ & Constr. \\
\hline 0,40 & As pessoas buscam criar novos conhecimentos & $\mathrm{C}$ & Constr. \\
\hline
\end{tabular}

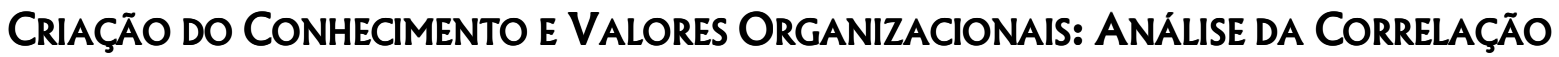

O tratamento de dados relativos à escala Inventário de Perfis de Valores Organizacionais [IPVO] foi realizado considerando a composição dos fatores identificados por Oliveira e Tamayo (2004) e calculando-se o índice de confiabilidade Alpha de Cronbach de cada um desses fatores.

Estes foram os coeficientes alpha encontrados para cada um dos fatores: Realização $\rightarrow 0,8897$; Conformidade $\rightarrow 0,7707$; Domínio $\rightarrow 0,7424$; Bem Estar do Empregado $\rightarrow$ 0,9215; Tradição $\rightarrow$ 0,7463; Prestígio $\rightarrow$ 0,8693; Autonomia $\rightarrow 0,9150$; Preocupação com a Coletividade $\rightarrow 0,8907$.

Cabe salientar que os índices de confiabilidade da amostra foram iguais ou superiores aos índices apresentados pela amostra no estudo desenvolvido pelos autores da escala.

Após o cálculo da confiabilidade dos fatores da escala Inventário de Perfis de Valores Organizacionais [IPVO], procedeu-se ao cálculo dos índices de correlação entre aqueles e os fatores da escala de Criação do Conhecimento Organizacional, tendo em vista atender ao objetivo geral proposto para o estudo.

Os resultados indicam que todos os valores organizacionais mensurados pela escala IPVO apresentam correlação positiva com todos os fatores da Escala Criação do Conhecimento Organizacional, quer com relação às condições capacitadoras quer quanto ao processo de conversão, exceto o valor Tradição.

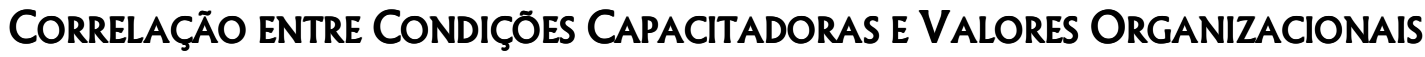

O fator Estímulo aos Desafios mostra-se mais fortemente associado aos valores Autonomia, Realização, Preocupação com a Coletividade e Bem-Estar do Empregado. Isto indica que quanto mais a organização valoriza a busca de aperfeiçoamento constante, a curiosidade, a variedade de experiências, a competência e o relacionamento com pessoas que são próximas à comunidade e o bem- 
estar do empregado, mais consegue desenvolver a capacidade de estimular os empregados a enfrentar desafios e vice-versa (Tabela 6).

O fator Compromisso com a Empresa está mais fortemente associado aos valores organizacionais Realização e Autonomia, indicando que, quanto mais a empresa valoriza a competência dos empregados e a autonomia, mais os empregados se sentem comprometidos com ela e vice-versa (Tabela 6).

O fator Processo Decisório Participativo mostrou-se mais fortemente correlacionado com os valores Realização, Autonomia e Preocupação com a Coletividade (Tabela 6).

O fator Orientação ao Ambiente Externo apresentou a correlação mais forte com o valor Preocupação com a Coletividade.

É interessante notar que, embora todos os fatores relativos às condições capacitadoras tenham mostrado correlação positiva com os valores organizacionais, excetuando-se Tradição, conforme já foi dito, é com o fator Orientação para o Ambiente externo que mantém as correlações menos elevadas, indicando que os valores organizacionais estão mais associados a fatores de criação do conhecimento relativos a aspectos internos da organização.

\section{CoRrelaÇÃo entre ConVERSÃo do CONHECIMENTO E VAlORES ORGANIZACIONAIS}

O processo de conversão de conhecimento obteve a correlação mais elevada com o valor organizacional Autonomia, seguido de Realização e Bem-Estar do Empregado (Tabela 7).

Em outra perspectiva, tem-se que os valores organizacionais que apresentam correlações mais elevadas com a criação do conhecimento são Realização, Bem-Estar do Empregado, Autonomia e Preocupação com a Coletividade.

Tabela 6: Correlação entre Valores Organizacionais e Fatores de Criação do Conhecimento

\begin{tabular}{|c|c|c|c|c|c|c|}
\hline & & \multicolumn{5}{|c|}{ Criação do Conhecimento } \\
\hline & & $\begin{array}{c}\text { Estímulo } \\
\text { aos } \\
\text { Desafios }\end{array}$ & $\begin{array}{c}\text { Compromisso } \\
\text { com a } \\
\text { Empresa } \\
\end{array}$ & $\begin{array}{c}\text { Processo } \\
\text { Decisório } \\
\text { Participativo } \\
\end{array}$ & $\begin{array}{c}\text { Orientação ao } \\
\text { Ambiente } \\
\text { Externo } \\
\end{array}$ & $\begin{array}{l}\text { Conversão do } \\
\text { Conhecimento }\end{array}$ \\
\hline $\mathbf{y}$ & Realização & $0,796 * *$ & $0,748^{* *}$ & $0,627^{* *}$ & $0,499 * *$ & $0,602 * *$ \\
\hline $\begin{array}{l}\mathbf{a} \\
\mathbf{l}\end{array}$ & Conformidade & $0,561 * *$ & $0,412^{* *}$ & $0,346^{* *}$ & $0,293 * *$ & $0,369^{* *}$ \\
\hline $\mathbf{o}$ & Domínio & $0,553 * *$ & $0,593^{* *}$ & $0,296^{* *}$ & $0,361 * *$ & $0,445^{* *}$ \\
\hline e & $\begin{array}{l}\text { Bem Estar do } \\
\text { Empregado }\end{array}$ & $0,750 * *$ & $0,644^{* *}$ & $0,558 * *$ & $0,268 * *$ & $0,694 * *$ \\
\hline $\begin{array}{l}\mathbf{O} \\
\mathbf{r} \\
\text { g. }\end{array}$ & Tradição & 0,097 & $-0,003$ & $0,040 * *$ & $-0,018$ & -0.050 \\
\hline
\end{tabular}


(conclusão)

Tabela 6: Correlação entre Valores Organizacionais e Fatores de Criação do Conhecimento

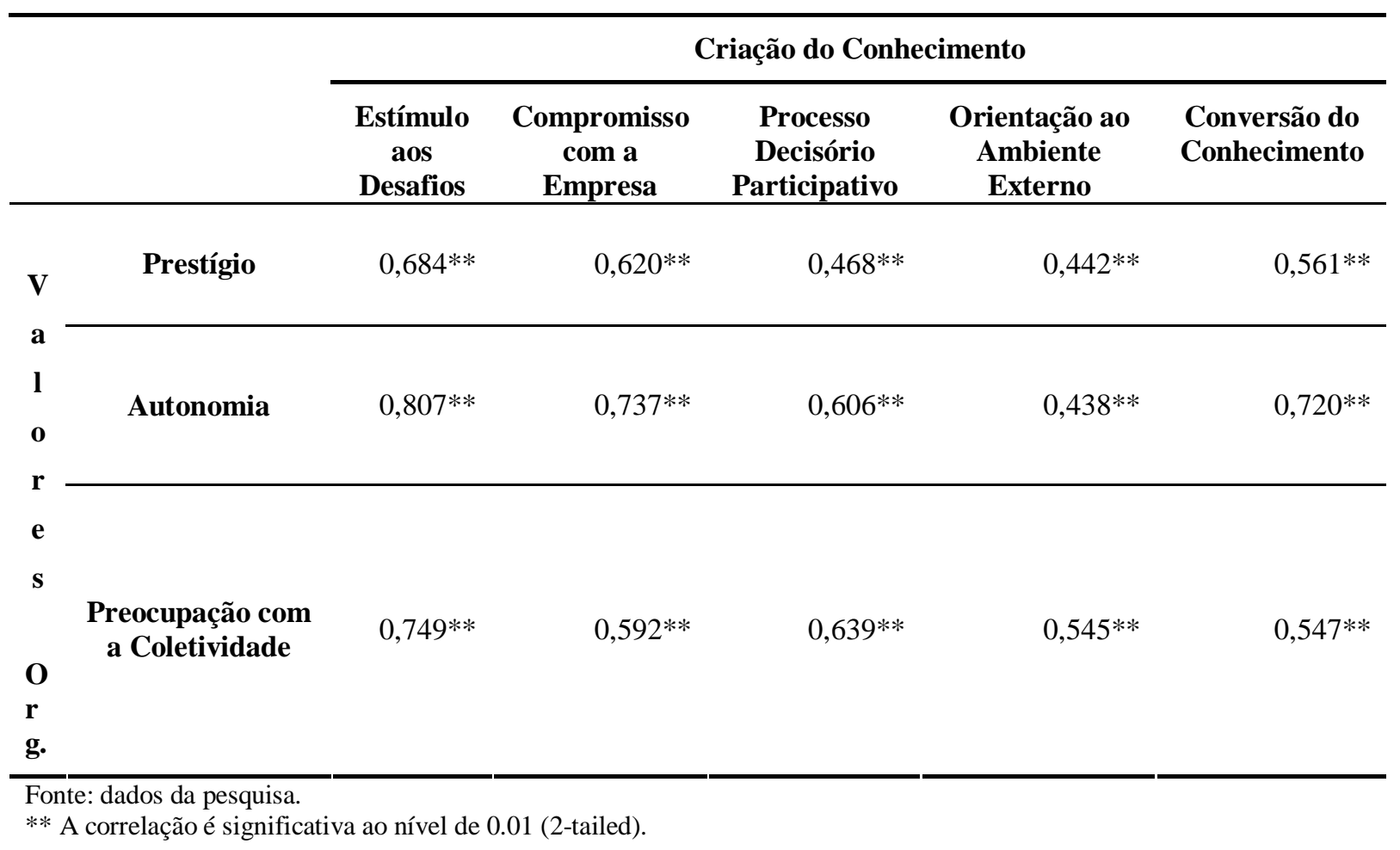

Por outro lado, os valores Autonomia, Bem-Estar do Empregado e Realização encontram-se situados numa zona de compatibilidade que envolve as dimensões Abertura à Mudança e Autopromoção, enquanto a Preocupação Coletividade se situa na dimensão Auto-Transcendência, pólo oposto à Autopromoção. Isto sugere que o valor Preocupação com a Coletividade atua como fator restritivo da Autopromoção, no que se refere à Criação do Conhecimento, evitando uma autopromoção a qualquer custo. Pode-se entender, então, que o estímulo ao enfrentamento de desafios, o compromisso do empregado com a empresa, o processo decisório participativo e a conversão do conhecimento, fatores de criação do conhecimento, estão associados com a abertura à mudança e autopromoção, levando em consideração a preocupação com a coletividade.

\section{CONCLUSÃO}

Os resultados evidenciaram indícios de corroboração da hipótese proposta para o estudo, uma vez que foi desenvolvido em uma amostra não-probabilística, o que demanda aprofundar em outros estudos a relação entre valores organizacionais e criação do conhecimento.

Dentro dos limites da amostra, a primeira conclusão do estudo diz respeito à aprendizagem como condição capacitadora. $\mathrm{O}$ fato de não se ter encontrado um fator composto especificamente de assertivas relativas à aprendizagem indica que ela em si não constitui condição separada das demais, mas integra os fatores Estímulo ao Enfrentamento de Desafios e Processo Decisório Participativo. Por outro lado, o fato de ter integrado aqueles fatores, e não ter integrado o fator Conversão do Conhecimento, significa que este não é percebido pelos respondentes como processo de aprendizagem, bem como que aprendizagem assume um sentido mais amplo, possibilitando a participação no processo decisório e contribuindo para que as pessoas corram riscos e assumam desafios. Essa 
percepção da aprendizagem é compatível com a concepção construtivista e com o conceito de aprendizagem de circuito triplo proposta por Argyris (1977).

Os fatores de criação do conhecimento Estímulo ao Enfrentamento de Desafios, Compromisso Consciente com a Empresa, Processo Decisório Participativo e Conversão do Conhecimento surgem como os que estão mais fortemente correlacionados e de forma positiva com os valores organizacionais Autonomia, Realização, Bem-Estar do Empregado, Realização e Preocupação com a coletividade. Isto significa que as empresas que foram percebidas pelos empregados respondentes como aquelas que oferecem estímulos para enfrentarem desafios e participarem de processos decisórios são também as que oferecem possibilidade de agir com independência, valorizando competência, qualidade de vida no trabalho e relacionamento com a comunidade. Ao agirem assim, também estimulam o compromisso do empregado com a empresa e processos de conversão do conhecimento.

Tem-se que, predominantemente, são as dimensões de valores organizacionais e abertura à mudança e autopromoção que guiam o comportamento das organizações na criação do conhecimento. A dimensão autotranscendência, representada pelo valor Preocupação com a Coletividade, parece entrar no processo, modificando e orientando o comportamento de autopromoção, de forma a não ultrapassar o respeito ao outro. Isto tem sentido, uma vez que, para criar conhecimento como propuseram Nonaka e Takeuchi (1997), a criação do conhecimento organizacional implica criar em conjunto, em processo de cooperação mútua.

O valor organizacional Tradição não se apresentou correlacionado à criação do conhecimento. Este resultado era esperado, uma vez que, ao se escolher para participar da amostra respondentes da área de desenvolvimento de produto, áreas em que, em princípio, a inovação enfaticamente ocorre, não se esperava que a dimensão de valores organizacionais Conservação fosse uma das principais na orientação do comportamento dessa área na criação do conhecimento.

Chamaram também a atenção as baixas correlações entre o fator Orientação ao Ambiente Externos e os valores organizacionais. Isto indica que os valores organizacionais, nas organizações pesquisadas, considerando as funções de integração interna e de adaptação externa apontadas por Meglino e Ravlin (1998), atendem mais à primeira do que à segunda. Este resultado conduz ao questionamento sobre se é esta uma peculiaridade das áreas de desenvolvimento de produto das empresas estudadas, ou se será comum a essa área de atuação. Mais ainda, teriam os valores organizacionais um papel mais forte na integração interna da organização do que na adaptação ao meio externo? Estes são tópicos que merecem ser pesquisados.

Outro aspecto interessante a ser ressaltado é que a aprendizagem geradora de criação do conhecimento, embora de natureza predominantemente construtivista, engloba aspectos tradicionais, estes relacionados ao alcance de metas organizacionais e de respeito aos valores da organização. Esta característica do processo de aprendizagem aparece sustentada nos valores organizacionais, uma vez que estão correlacionados positivamente aos fatores de criação do conhecimento em que a aprendizagem surge inserida. Isto indica que, embora a aprendizagem deva estar calcada num processo com características construtivistas, deve inserir-se dentro de um contexto de limite de liberdade, o que pode parecer um paradoxo organizacional: criar com liberdade, porém tendo por base os valores e as metas organizacionais.

Esse paradoxo parece natural, olhando-se para a natureza do contexto organizacional, o que não evita que se faça referência ao papel dessa aprendizagem e dos valores organizacionais que a sustentam no desenvolvimento do indivíduo como ser social e político; este, ao se valer de aspectos construtivistas, parece ficar restringido no seu potencial de vir-a-ser. 
Além do limite do tipo de amostra (não-probabilística), que não permite generalizações, a escala de criação do conhecimento criada contempla, entre as suas assertivas, duas que consistem em valores. Isto evidencia que, apesar dos elevados índices de confiabilidade, ela ainda pode ser aperfeiçoada.

A relação entre valores organizacionais e criação do conhecimento merece ser explorada em outras pesquisas, visando à compreensão do fenômeno da inovação. Sugerem-se estudos em outras áreas organizacionais, em empresas de portes diferentes, em matrizes e subsidiárias de empresas multinacionais, objetivando compreender também qual o papel dos valores culturais na relação entre valores organizacionais e a criação do conhecimento, uma vez que organizações multinacionais podem apresentar diferenças comportamentais significativas em função da cultura do país de que sejam originárias.

Artigo recebido em 25.02.2007. Aprovado em 18.04.2008.

\section{REFERENNCIAS BIBLIOGRÁFICAS}

Argyris, C. (1977, September). Double loop learning in organizations. Harvard Business Review, pp. 115-125.

Argyris, C., \& Schon, D. A. (1978). Organizational learning: a theory of action perspective. Reading Massachusetts: Addison Wesley.

Barnard, C. (1938). Functions of executive. Cambridge, MA: Harvard University.

Baker, A. C., Jensen, P. J., \& Kolb, D. A. (2002). Conversational learning: an experiential approach to knowledge creation. Westport: Quorum Books.

Bierly, P., \& Chakrabarti, A. (1996). Generic knowledge strategies in the U.S. Pharmaceutical Industry. Strategic Management Journal, 17 (Winter Special Issue), 123-135.

Bontis, N. (1999). Managing organizational kowledge by diagnosing intelectual capital: framing and advancing the state of the field. International Journal of Technology Management, 18(5-8), 433-462.

Campos, C. (2001). A organização inconformista: como identificar e transformar mentes revolucionárias em um diferencial competitivo. São Paulo: Editora FGV.

Connor, P. E., \& Becker, B. W. (1975). Values and the organization: suggestion for research. Academy of Management Journal, 18(3), 550-561.

Coutinho, L. G. (1994). Superação da fragilidade tecnológica e a ausência de cooperação. In E. V. Musa, J. E. Ripper Filho, L. Meis, L. G. Coutinho, M. F. M. Arruda, M. Nussenzueig, N. B. Araújo, R. L. L., Silva Filho, W. A. Mannheimer. Ciência e tecnologia: alicerces do desenvolvimento. São Paulo: Cobram.

Coutinho, L. G., \& Ferraz, J. C. (1995). Estudo da competitividade da indústria brasileira. Campinas: Papirus.

Crossan, M. M., Lane, H. W., \& White, R. G. (1999). Na organizational learning framework: from intuition to institution. Academy of Management Review, 24(3), 522-537.

Daft, R. L., \& Weick, K. E. (1984). Toward a models of organizations as interpretation systems. Academy of Management Review, 9(2), 284-295. 
Drucker, P. F. (1991). As novas realidades: no governo e na política, na economia e nas empresas, na sociedade e na visão do mundo. São Paulo: Pioneira.

Ferraz, J. C. Kupfer, D., \& Haguenauer, L. (1996). Made in Brazil. Rio de Janeiro: Campus.

Fleury, M. T. L., \& Oliveira, M. R. M., Jr. (2002) Aprendizagem e gestão do conhecimento. In M. T. L. Fleury (Org.). As pessoas na organização. São Paulo: Gente

Freeman, C. (1988) Introduction. In Dosi, G. et al. Technical change and economic theory. Londres: Pinter Publishers.

Garvin, D. A. (1993). Building a learning organization. Harvard Business Review, 71(4), 78-92.

Hair, J. F., Jr., Anderson, R. E., Tatham, R. L., \& Black, W.C. (1998). Multivariate data analysis. New Jersey: Prentice Hall.

Hair, J. F., Jr., Anderson, R. E., Tatham, R. L., \& Black, W.C (2005). Análise multivariada de dados (5. ed.). Porto Alegre: Bookman.

Kim, D. H. (1993). O elo entre a aprendizagem individual e a aprendizagem organizacional. In D. A. Klein. A gestão estratégica do capital intelectual (Cap. 4). Rio de Janeiro: Qualitymark.

Kogut, B., \& Zander, U. (1992). Knowledge of the firm, combinative capabilities, and the replication of technology. Organization Science, 3(3), 383-397.

Kolb, D. A. (1997). A gestão e o processo de aprendizagem. In K. Starkey (Org.). Como as organizações aprendem: relatos do sucesso das grandes empresas. São Paulo: Futura.

Krogh, G. von, Ichijo, K, \& Nonaka, I. (2001). Facilitando a criação de conhecimento. Rio de Janeiro: Campus.

Leonard-Barton, D., \& Sensiper, S. (1998). The role of tacit knowledge in group innovation. California Management Review, 40(3), 112-129.

Ludvall, B. (1992). National systems of innovation: towards a theory of innovation and interactive learning. Londres: Pinter Publishers.

Meglino, B. M., \& Ravlin, E. C. (1998). Individual values in organizations: concepts, controversies, and research. Journal of Management, 34(30), 351-389.

Mendes, A. M., \& Tamayo, A. (1999, setembro). Valores e vivências de prazer-sofrimento nas organizações. Anais do Encontro Nacional da Associação Nacional de Pós-Graduação e Pesquisa em Administração, Foz do Iguaçu, PR, Brasil, 23.

Mizukami, M. G. N. (1986). Ensino: as abordagens do processo. São Paulo: EPU.

Nonaka, I. (1997). A empresa criadora de conhecimento. In K. Starkey (Org.). Como as organizações aprendem: relatos do sucesso das grandes empresas. São Paulo: Futura.

Nonaka, I., \& Takeuchi, H. (1997). Criação de conhecimento na empresa: como as empresas japonesas geram a dinâmica da inovação. Rio de Janeiro: Campus.

Nonaka, I., Toyama, R., \& Konno, N. (2000). SECI, BA and leadership. A unified model of dynamic knowledge creation. Long Range Planning, (33), 5-34.

Oliveira, A. F., \& Tamayo, A. (2004). Inventário de perfis de valores organizacionais. Revista de Administração de Empresas, 39(2), 129-140. 
Porter, M. (1992). Vantagem competitiva: criando e sustentando um desempenho superior. Rio de Janeiro: Campus.

Saban, K., Lanasa, J., Lackman, C., \& Pease, G. (2000). Organizational learning: a critical component to new product development. The Journal of Product and Brand Management, 9(2), 99-119.

Schwartz, S. H. (1992). Universals in the content and structure of values: theoretical advances and empirical tests in 20 countries. Advances in Experimental Social Psychology, 25, 1-65.

Selltiz, C. (1967). Métodos de pesquisa nas relações sociais. São Paulo: Edgard Blücher.

Spender, J. C., \& Grant, R. M. (1996). Knowledge and the firm: overview. Strategic Management Journal, 17(Winter Special Issue), 5-9.

Tamayo, A., \& Borges, L. O. (2001). Valores del trabajo y valores de las organizaciones. In M. Ros \& \& V. V.Gouveia (Coords.). Psicología social de los valores humanos: desarrollos teóricos, metodológicos y aplicados. Madrid: Editorial Biblioteca Nueva.

Tamayo, A., \& Gondim, M. G. C. (1996). Escala de valores organizacionais. Revista de Administração, 31(2), 62-72.

Walsh, J. P., \& Rivera, G. U. (1991). Organizational memory. The Academy of Management Review, 16(1), 57-91.

Zack, M. (1999). Management of codified knowledge. Sloan Mangement Review, 40(4), 45-58. 